\title{
BMJ Open Levels of Lipoprotein (a) in patients with coronary artery disease with and without inflammatory rheumatic disease: a cross-sectional study
}

\author{
Sverre Holm, ${ }^{1,2}$ Ingvild Oma, ${ }^{3,4}$ Tor-Arne Hagve, ${ }^{4,5}$ Kjell Saatvedt, ${ }^{6}$ \\ Frank Brosstad, ${ }^{1,4}$ Knut Mikkelsen, ${ }^{2}$ Hans Rydningen, ${ }^{7}$ Ivar Risnes, ${ }^{7}$ \\ Sven Martin Almdahl, ${ }^{8}$ Thor Ueland, ${ }^{1,4}$ Pål Aukrust, ${ }^{1,4,9}$ Bente Halvorsen, ${ }^{1,4}$ \\ Ivana Hollan $2,3,10,11$
}

To cite: Holm S, Oma I, Hagve T-A, et al. Levels of Lipoprotein (a) in patients with coronary artery disease with and without inflammatory rheumatic disease: a crosssectional study. BMJ Open 2019;9:e030651. doi:10.1136/ bmjopen-2019-030651

- Prepublication history for this paper is available online. To view these files please visit the journal online (http://dx.doi org/10.1136/bmjopen-2019030651).

Received 25 March 2019 Revised 5 April 2019 Accepted 10 April 2019
A) Check for updates

(C) Author(s) (or their employer(s)) 2019. Re-use permitted under CC BY-NC. No commercial re-use. See rights and permissions. Published by BMJ.

For numbered affiliations see end of article.

Correspondence to

Dr. Sverre Holm;

sverre.holm@rr-research.no

\section{ABSTRACT}

Objectives Patients with various inflammatory rheumatic diseases (IRDs) have increased risk of atherothrombotic disease. Lipoprotein (a) (Lp(a)) is a risk factor for atherosclerosis but its role in IRD with accompanying coronary artery disease (CAD) is still unclear. We aimed to examine if serum $L p(a)$ levels differed between CAD patients with and without accompanying IRD.

Design A cross-sectional observational, patient-based cohort study.

Setting Referred centre for coronary artery bypass grafting in the South Eastern part of Norway. Participants 67 CAD patients with IRD (CAD/IRD) and 52 CAD patients without IRD (CAD/non-IRD). All patients were Caucasians, aged $>18$ years, without any clinically significant infection or malignancy.

Methods $L p(a)$ levels in serum were analysed by particle enhanced immunoturbidimetric assay, and Lp(a) levels were related to clinical and biochemical characteristics of the patient population.

Results We found no differences in serum levels of $L p(a)$ between CAD patients with and without IRD. In general, we found that $L p(a)$ correlated poorly with clinical and biochemical parameters including $\mathrm{C}$ reactive protein with the same pattern in the CAD/non-IRD and CAD/IRD groups. Conclusions Our data do not support a link between inflammation and $L p(a)$ levels in CAD and in general $L p(a)$ levels were not correlated with other risk factors for cardiovascular disease.

\section{INTRODUCTION}

Patients with inflammatory rheumatic diseases (IRDs) have increased cardiovascular risk, primarily due to accelerated atherothrombosis. $^{1-4}$ The reasons are not fully understood, but seem to involve chronic inflammation as a common mediator of both IRD and atherosclerosis. ${ }^{56}$ Thus, persistent chronic inflammation in IRD patients has been shown to contribute both to accelerated atherosclerosis ${ }^{7}$ and cardiovascular events. ${ }^{8}$

\section{Strengths and limitations of this study}

- The study investigates a unique and well characterised group of patients.

- We present measurement of Lipoprotein (a) in two distinct coronary artery disease populations, that is, patients with and without accompanying inflammatory rheumatic disease.

- The main limitation of the study is the relatively small sample size.

- Another limitation is that the design of the study does not allow for confirming of any cause-effect relationships.

Besides chronic inflammation, traditional cardiovascular risk factors and genetic components are also implicated in the increased risk of cardiovascular disease (CVD) observed in patients with chronic IRD. ${ }^{9}$

Lipoprotein $(a)^{10}(\operatorname{Lp}(a))$ is composed of a low-density lipoprotein (LDL)-like particle bound with a cringle-structured glycoprotein, named apolipoprotein (apo) (a). ${ }^{11} 12$ Epidemiological studies have suggested that elevated levels of $\operatorname{Lp}(\mathrm{a})$ is a significant risk factor for atherosclerotic disorders including myocardial infarction (MI) and ischaemic stroke. ${ }^{12} 13$ In those with established coronary artery disease $(\mathrm{CAD})$, high $\mathrm{Lp}(\mathrm{a})$ levels are associated with increased cardiovascular risk. ${ }^{10} 12$ Moreover, $\mathrm{Lp}(\mathrm{a})$ seems to be a marker of atherosclerotic disorders and to exert both proatherogenic and prothrombotic effects, some of which are primarily related to the LDL component whereas others are apo(a)-dependent. ${ }^{12} 14$

Interestingly, besides genetic factors, also inflammation may influence $\operatorname{Lp}(\mathrm{a})$ levels. In support of this notion, interleukin 6 (IL-6) inhibition has been shown to down-regulate 
Lp(a) levels in patients with IRD..$^{15}$ Moreover, we have previously demonstrated that methotrexate and tumour necrosis factor inhibition down-regulate $\operatorname{Lp}(\mathrm{a})$ in patients with rheumatoid arthritis (RA) ${ }^{16}$ In contrast, the majority of lipid-lowering strategies, except for lipid apheresis, have little influence on $\mathrm{Lp}(\mathrm{a})$ levels. ${ }^{1718}$

$L p(a)$ levels have been reported to be elevated in IRDs including RA and systemic lupus erythematosus (SLE). ${ }^{19}$ However, it is still unclear if the increased levels of $\operatorname{Lp}(\mathrm{a})$ in IRDs is modified by accompanying CAD. Our aim in this study was to investigate if $\operatorname{Lp}(\mathrm{a})$ levels differed between CAD patients with and without accompanying IRD. Our secondary aim was to examine if $L p(a)$ levels were associated with relevant clinical and laboratory variables in these patients.

\section{MATERIALS AND METHODS \\ Study population}

From the Norwegian Feiring Heart Biopsy Study, described elsewhere, ${ }^{2021}$ we examined CAD patients with IRD (CAD/IRD group; $\mathrm{n}=67$ ) and CAD patients without IRD (CAD/non-IRD group; n=52). Briefly, all patients were Caucasians, aged $>18$ years, without any clinically significant infection or malignancy. The CAD groups were recruited among patients referred to coronary artery bypass grafting (CABG) due to $\mathrm{CAD}$. The IRD diagnoses were confirmed according to accepted diagnostic criteria. ${ }^{21}$ The patients were consecutively enrolled in the study. The $\mathrm{CAD} / \mathrm{IRD}$ and $\mathrm{CAD} /$ non-IRD groups were matched for age and sex at group level.

The CAD/IRD group consisted of patients with RA $(n=24)$, polymyalgia rheumatica $(n=15)$, psoriatic arthritis $(\mathrm{n}=10)$, ankylosing spondylitis $(\mathrm{n}=6)$, giant cell arteritis $(\mathrm{n}=6)$, SLE $(\mathrm{n}=3)$, primary Sjögren's syndrome $(\mathrm{n}=1)$, reactive arthritis $(n=1)$ and undifferentiated connective tissue disease $(n=1)$.

\section{Data collection}

The CAD groups were examined by interview, physical examination, self-reported questionnaires and blood tests within 2 days before CABG. A positive family history of $\mathrm{CAD}$ was defined as $\mathrm{CAD}$ in first-degree relatives at age $<65$ years and hypercholesterolaemia as a total serum cholesterol level $>5.5 \mathrm{mmol} / \mathrm{L}$ registered in medical records, or use of lipid-lowering drugs. ${ }^{20}$

\section{Blood sampling protocol}

Venous blood samples were collected after a minimum of 4 hours fasting. The samples were collected in sterile containers with EDTA (plasma) or without additives (serum). The EDTA tubes were immediately immersed in melting ice, and centrifuged within $30 \mathrm{~min}$ (2000 $\mathrm{g}$ for $10 \mathrm{~min})$. The serum tubes were centrifuged after coagulation in room temperature $(<2$ hours). Plasma and serum were stored at $-75^{\circ} \mathrm{C}$ in multiple aliquots, and sent to the respective laboratory on dry ice. Samples were not thawed prior to the laboratory analyses, and they were analysed in batches, in random order and in a blinded manner.

\section{Lp(a) assay}

$\mathrm{Lp}$ (a) levels in serum were analysed by particle enhanced immunoturbidimetric assay, LPALX Tina-quant Lp(a) (Latex) (Roche, Rotkreuz, Switzerland). The precipitate was determined turbidimetrically at $552 \mathrm{~nm}$, using Cobasc 501 system from Roche.

\section{Miscellaneous}

Plasma concentrations of plasminogen activator inhibitor were analysed by enzyme immunoassay provided from R\&D Systems (Minneapolis, Minnesota, USA). Serum levels of C-reactive protein (CRP) were determined using a particle-enhanced, high-sensitive immunoturbidimetric assay (Tina-Quant CRP Gen.3, Roche). Routine test standards of the hospital laboratory were used to analyse erythrocyte sedimentation rate, leucocytes, neutrophils, triglycerides, total cholesterol, high-density lipoprotein (HDL) cholesterol and LDL cholesterol and uric acid.

\section{Statistical analyses}

Distributions of categorical variables were compared using $\chi^{2}$ test. Comparisons of continuous variables in two groups were performed using Student's t-test (normally distributed variables) or Mann-Whitney U-test (non-normally distributed variables). The $\mathrm{p}$ values (two-sided) were considered significant when $<0.05$.

\section{Patient and public involvement}

The outcomes measures were selected based on the current level of evidence, which aims to contribute to the provision of the missing pieces. The plan for the study was developed in accordance with suggestions given by representatives and members of patient organisations, in particular the Norwegian Rheumatism association during frequent meetings/lectures about CVD in IRD. The patients wished to clarify reasons for the increased CV risk in IRD, especially with the aim to identify factors that could be possible to modify, and therefore ameliorate CVD morbidity and mortality in these diseases. The patients themselves were not involved in recruitment and conduction of the study. As for other substudies from this biobank, also this study will be disseminated to IRD patients through lectures for patient organisations and/ or through popular scientific information in magazines published by these organisations.

\section{RESULTS}

\section{Characteristics of the cohort}

Characteristics of the study population are shown in table 1. Except for the use of immunosuppressive drugs, the two CAD groups were matched for most of the parameters. However, the CAD/IRD group had more often a history of previous acute coronary syndrome (ACS) and higher CRP levels (table 1). 


\begin{tabular}{|c|c|c|c|}
\hline & $\begin{array}{l}\text { CAD/non- } \\
\text { IRD (n=52) }\end{array}$ & $\begin{array}{l}\text { CAD/IRD } \\
(n=67)\end{array}$ & P value* \\
\hline Age, years & $68 \pm 10$ & $67 \pm 10$ & 0.684 \\
\hline Men & $34(65.4 \%)$ & $42(62.7 \%)$ & 0.761 \\
\hline Body mass index, $\mathrm{kg} / \mathrm{m}^{2}$ & $25.7 \pm 3.3$ & $25.5 \pm 4.3$ & 0.822 \\
\hline \multicolumn{4}{|l|}{ Medical history } \\
\hline History of MI & $23(44.2 \%)$ & $38(56.7 \%)$ & 0.177 \\
\hline ACS & $10(19.2 \%)$ & $19(28.4 \%)$ & 0.005 \\
\hline Family history of CAD & $42(80.8 \%)$ & $49(74.2 \%)$ & 0.402 \\
\hline Diabetes & $3(5.8 \%)$ & $2(3.2 \%)$ & 0.509 \\
\hline Hypertension & $30(57.7 \%)$ & $40(60.6 \%)$ & 0.749 \\
\hline Hyperlipidaemia & $46(88.5 \%)$ & $56(83.6 \%)$ & 0.691 \\
\hline Previous smoker & $25(48.1 \%)$ & $26(38.8 \%)$ & 0.311 \\
\hline Current smoker & $7(13.5 \%)$ & $15(22.4 \%)$ & 0.213 \\
\hline \multicolumn{4}{|l|}{ Biochemistry } \\
\hline Cholesterol, mmol/L & $4.91 \pm 1.17$ & $4.92 \pm 1.28$ & 0.966 \\
\hline HDL, mmol/L & $1.21 \pm 0.32$ & $1.25 \pm 0.36$ & 0.556 \\
\hline LDL, mmol/L & $3.18 \pm 0.96$ & $3.12 \pm 1.05$ & 0.761 \\
\hline $\mathrm{TG}, \mathrm{mmol} / \mathrm{L}$ & $1.53 \pm 0.79$ & $1.61 \pm 0.71$ & 0.604 \\
\hline PAl-1, ng/mL & $\begin{array}{l}19.1(13.4 \\
26.8)\end{array}$ & $\begin{array}{l}20.1(13.5 \\
28.8)\end{array}$ & 0.600 \\
\hline $\begin{array}{l}\text { C reactive protein, } \\
\mathrm{mg} / \mathrm{L}\end{array}$ & $2.3(1.2,4.4)$ & $5.2(2.3,14.0)$ & $<0.001$ \\
\hline \multicolumn{4}{|l|}{ Medication } \\
\hline Oral glucocorticoids & $0(0 \%)$ & $27(40.3 \%)$ & $<0.001$ \\
\hline DMARDS & $0(0 \%)$ & $22(33.3 \%)$ & $<0.001$ \\
\hline coX2 inhibitors & $0(0 \%)$ & $11(16.4 \%)$ & $<0.001$ \\
\hline NSAID & $0(0 \%)$ & $9(13.4 \%)$ & $<0.001$ \\
\hline Lipid lowering drugs & $42(80.8 \%)$ & $50(75.8 \%)$ & 0.514 \\
\hline Acetylsalisylic acid & 47 (90.4\%) & 57 (85.1\%) & 0.387 \\
\hline Beta-blockers & 42 (80.8\%) & 50 (74.6\%) & 0.427 \\
\hline ACE inhibitors & 18 (34.6\%) & 21 (31.3\%) & 0.706 \\
\hline $\begin{array}{l}\text { Duration of IRD, } \\
\text { months }\end{array}$ & - & $168(73,260)$ & \\
\hline
\end{tabular}

Data are presented as $n(\%)$, mean \pm SD or median (25th, 75th percentile) depending on variable type and distribution. ${ }^{*} \mathrm{P}$ value from Student's t-test, Mann-Whitney $\mathrm{U}$ test or $\mathrm{X}^{2}$ test depending on type and distribution of data.

ACS, acute coronary syndrome; CAD, coronary artery disease; COX2, cyclooxygenase 2; DMARDS, disease-modifying antirheumatic drugs; HDL, high-density lipoprotein; IRD, inflammatory rheumatic disease; LDL, low-density lipoprotein; MI, myocardial infarction; NSAID, non-steroidal antiinflammatory drugs; PAI-1, plasminogen activator inhibitor 1; TG, triglycerides.

\section{Serum LP(a) levels in CAD/IRD and CAD/non-IRD patients}

As illustrated in figure 1, serum levels of $\operatorname{Lp}(\mathrm{a})$ were similar, with no significant differences between the $\mathrm{CAD}$ / IRD and CAD/non-IRD groups. As ACS and CRP was not associated with $\operatorname{Lp}(\mathrm{a})$ (see below), no adjustments were

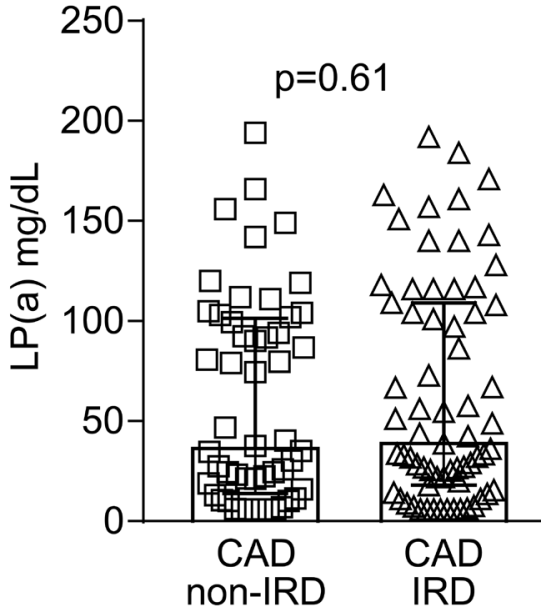

Figure $1 \mathrm{Lp}(\mathrm{a})$ levels in CAD patients with $(n=67)$ and without IRD $(n=52)$. In addition to individual values, the figure shows median and 25th and 75th percentile levels. The comparison between the groups was performed by the Mann-Whitney U-test. CAD, coronary artery disease; IRD, inflammatory rheumatic disease; Lp(a), lipoprotein (a).

made when comparing levels between $\mathrm{CAD} / \mathrm{IRD}$ and $\mathrm{CAD} /$ non-IRD groups.

\section{Associations between $\mathrm{Lp}(\mathrm{a})$ and relevant clinical and demographic variables}

In general, Lp(a) correlated poorly with clinical and biochemical parameters in the study population as a whole, with the same pattern in CAD/IRD and CAD-non-IRD patients. This included correlations with age, gender and body mass index, medical history, biochemical parameters and medications, including CRP and a history of ACS that differed between the two CAD groups (table 2). However, Lp(a) correlated significantly with LDL-cholesterol in the study group as a whole, mainly reflecting a positive correlation in the $\mathrm{CAD} /$ non-IRD group (table 2). Moreover, whereas HDL cholesterol correlated positively with $\mathrm{Lp}(\mathrm{a})$ in the $\mathrm{CAD} /$ non-IRD group, $\mathrm{Lp}(\mathrm{a})$ was inversely correlated with HDL cholesterol in the CAD/IRD group (table 2).

\section{DISCUSSION}

In the present study we found no differences in serum levels of $\operatorname{Lp}(\mathrm{a})$ between CAD patients with and without IRD. Moreover, we found that $\operatorname{Lp}(\mathrm{a})$ correlated poorly with clinical and biochemical parameters including CRP with the same pattern in the CAD/non-IRD and CAD/ IRD groups. These data do not support the notion that $\mathrm{Lp}$ (a) levels are driven by inflammation, as reflected by CRP levels, in these populations.

Several studies have shown that elevated serum Lp(a) levels are associated with a higher risk for developing $\mathrm{CAD}$, and in those with established CAD, high levels of $\mathrm{Lp}(\mathrm{a})$ are associated with increased risk for cardiovascular events. ${ }^{10} 1213$ There are also some studies showing increased serum levels of $\operatorname{Lp}(\mathrm{a})$ in IRD patients, 
Table 2 Correlations between serum levels of Lp(a) and different clinical and biochemical characteristics of the study population

\begin{tabular}{|c|c|c|c|}
\hline & $\begin{array}{l}\text { All } \\
(n=119)\end{array}$ & $\begin{array}{l}\text { CAD/non- } \\
\text { IRD (n=52) }\end{array}$ & $\begin{array}{l}\text { CAD/IRD } \\
(n=67)\end{array}$ \\
\hline Age, years & -0.01 & -0.01 & -0.02 \\
\hline Men & -0.01 & $0.27^{*}$ & -0.22 \\
\hline Body mass index & 0.09 & 0.03 & 0.13 \\
\hline \multicolumn{4}{|l|}{ Medical history } \\
\hline History of MI & 0.01 & -0.14 & 0.10 \\
\hline ACS & -0.05 & -0.10 & -0.03 \\
\hline Family history of CAD & -0.05 & 0.11 & -0.16 \\
\hline Diabetes & -0.18 & -0.14 & -0.21 \\
\hline Hypertension & 0.05 & 0.04 & 0.04 \\
\hline Hyperlipidaemia & 0.00 & -0.11 & 0.06 \\
\hline Previous smoker & 0.00 & -0.03 & 0.02 \\
\hline Current smoker & -0.09 & -0.24 & -0.01 \\
\hline \multicolumn{4}{|l|}{ Biochemistry } \\
\hline Cholesterol & 0.20 & 0.29 & 0.13 \\
\hline HDL & -0.02 & $0.37^{*}$ & $-0.29^{*}$ \\
\hline LDL & $0.22^{*}$ & $0.30^{*}$ & 0.17 \\
\hline $\mathrm{TG}$ & 0.04 & 0.06 & 0.04 \\
\hline PAl-1 & 0.02 & 0.00 & 0.04 \\
\hline $\mathrm{C}$ reactive protein & 0.14 & -0.02 & 0.22 \\
\hline \multicolumn{4}{|l|}{ Medication } \\
\hline Oral glucocorticoids & -0.03 & - & -0.12 \\
\hline DMARDS & -0.09 & - & -0.15 \\
\hline COX2 inhibitors & 0.10 & - & 0.13 \\
\hline NSAID & 0.15 & - & 0.17 \\
\hline Lipid lowering drugs & 0.04 & 0.05 & 0.04 \\
\hline Acetylsalisylic acid & 0.13 & 0.15 & 0.12 \\
\hline Beta-blockers & -0.08 & -0.14 & -0.03 \\
\hline ACE inhibitors & 0.07 & -0.15 & 0.23 \\
\hline Duration of IRD, months & - & - & 0.09 \\
\hline
\end{tabular}

Data are given as Spearman correlation coefficients.

${ }^{*} \mathrm{P}<0.05$.

ACS, acute coronary syndrome; CAD, coronary artery disease; COX2, cyclooxygenase 2; DMARDS, disease-modifying antirheumatic drugs; HDL, high-density lipoprotein; IRD, inflammatory rheumatic disease; LDL, low-density lipoprotein; Lp (a), lipoprotein (a); MI, myocardial infarction; NSAID, non-steroidal anti-inflammatory drugs; PAI-1, plasminogen activator inhibitor 1; TG, triglycerides.

potentially associated with increased risk for developing atherosclerotic disease. ${ }^{19}$ These latter studies may indicate an interaction between $\operatorname{Lp}(\mathrm{a})$ and inflammation. However, herein we found no differences in $\operatorname{Lp}$ (a) levels between CAD/non-IRD and CAD/IRD patients, although the latter group had significantly higher CRP levels. Indeed, we found no correlation between $\operatorname{Lp}(\mathrm{a})$ and CRP with the same pattern in the two CAD groups. Moreover, whereas therapeutic intervention targeting IL- 6 by the IL-6 receptor inhibitor tocilizumab has been shown to down-regulate $\operatorname{Lp}(\mathrm{a})$ levels in patients with IRD, ${ }^{22-24}$ we recently observed no effect of tocilizumab treatment on $\mathrm{Lp}$ (a) levels in patients with Non-ST-elevation MI. ${ }^{25}$ Thus, at present the link between inflammation and $\operatorname{Lp}(\mathrm{a})$ levels is questionable, and our findings herein do not support the 'inflammatory-driven' $\mathrm{Lp}(\mathrm{a})$ hypothesis.

There are some reports of a positive correlation between $\operatorname{Lp}(\mathrm{a})$ and HDL cholesterol, ${ }^{26}$ and in the present study this was also seen in the $\mathrm{CAD} /$ non-IRD group. In contrast, an opposite association was seen in the CAD/ IRD, with a significant inverse correlation between $\mathrm{Lp}(\mathrm{a})$ and HDL cholesterol. At present we have no explanation for these different associations between HDL cholesterol and $\operatorname{Lp}(\mathrm{a})$ in the two CAD groups, and it could be by chance owing to a large number of correlation analyses. However, future studies exploring this pattern in larger study populations could potentially contribute to our understanding of the complex regulation of $\operatorname{Lp}(\mathrm{a})$ in GVD.

Although some correlation with LDL and HDL cholesterol, $\operatorname{Lp}(\mathrm{a})$ levels did not correlated with other risk factor for CAD. More recent studies have also noted that $\mathrm{Lp}$ (a) levels correlated poorly with other risk factors for CVD. ${ }^{27}$ This does, however, not exclude that $\operatorname{Lp}(\mathrm{a})$ could contribute to development and progression of atherosclerotic disorders. Thus, $\operatorname{Lp}(\mathrm{a})$ has been suggested to promote atherogenesis and plaque instability by inhibiting angiogenesis, enhancing endothelial cell activation and thrombogenesis through inhibiting fibrinolysis and tissue factor inhibitor pathway and inducing platelet activation. ${ }^{101214} \mathrm{Lp}(\mathrm{a})$ has also been shown to contribute to foam cell formation, and through binding to oxidised phospholipids it may cause plaque instability. ${ }^{12}$ If these mechanisms are operating in the same degree in CAD patients with and without accompanying IRD has to this end not been studied.

This study has some potential limitations. First, due to a relatively small sample size, the apparent lack of differences and associations might be caused by type-II error and our data should be interpreted with some cautions. Second, the design of the study does not allow for confirming of any cause-effect relationships.

In conclusion, we found no differences in $\operatorname{Lp}(\mathrm{a})$ levels between $\mathrm{CAD} / \mathrm{IRD}$ and $\mathrm{CAD} /$ non-IRD patients, and $\mathrm{Lp}$ (a) levels correlated poorly with other risk factors for CAD progression including CRP. Our data do not support a link between inflammation and Lp(a) levels in CVD.

\section{Author affiliations}

${ }^{1}$ Research Institute of Internal Medicine, Oslo University Hospital, Oslo, Norway ${ }^{2}$ Rheumatology Department, Hospital for Rheumatic Diseases, Lillehammer, Norway

${ }^{3}$ Department of Pathology, Sykehuset Innlandet HF Divisjon Lillehammer, Lillehammer, Norway

${ }^{4}$ Faculty of Medicine, Institute of Clinical Medicine, University of Oslo, Oslo, Norway ${ }^{5}$ Division of Diagnostics and Technology, Akershus University Hospital, Lorenskog, Norway 
${ }^{6}$ Department of Thoracic Surgery, Oslo University Hospital Rikshospitalet, Oslo, Norway

${ }^{7}$ Department of Cardiac Surgery, Feiring Heart Clinic, Feiring, Norway

${ }^{8}$ Department of Cardiothoracic and Vascular Surgery, University Hospital of North Norway, Tromso, Norway

${ }^{9}$ Section of Clinical Immunology and Infectious Diseases, Oslo University Hospital Rikshospitalet, 0slo, Norway

${ }^{10}$ Department of Medicine, Brigham and Women's Hospital, Boston, Massachusetts, USA

${ }^{11}$ Harvard Medical School, Harvard, Boston, USA

Acknowledgements We will thank the patient advisers from Norwegian Rheumatism association as well as Norwegian Women's Public Health Association and People with Heart and Lung Diseases for their support.

Contributors $\mathrm{SH}, \mathrm{IO}, \mathrm{BH}$ and $\mathrm{IH}$ conceived and design research; T-AH and FB performed biochemical analyses; IO, KS, KM, HR, IR, SMA and IH recruited patients and collected samples; SH, IO, TU and IH performed statistical analyses; SH, PA and IH wrote the paper; SH, PA, BH and IH had the responsibility for the final content. All authors read, critically revised and approved the final manuscript.

Funding This work was supported by grants from the South-Eastern Norway Regional Authority. We will also thank the Norwegian Rheumatism association as well as Norwegian Women's Public Health Association and People with Heart and Lung Diseases for financial support.

Competing interests None declared.

Patient consent for publication Not required.

Ethics approval The Regional Ethics Committee for Medical Research approved the study protocol.

Provenance and peer review Not commissioned; externally peer reviewed.

Data sharing statement All data presented in this study is available from the corresponding author upon reasonable request.

Open access This is an open access article distributed in accordance with the Creative Commons Attribution Non Commercial (CC BY-NC 4.0) license, which permits others to distribute, remix, adapt, build upon this work non-commercially, and license their derivative works on different terms, provided the original work is properly cited, appropriate credit is given, any changes made indicated, and the use is non-commercial. See: http://creativecommons.org/licenses/by-nc/4.0/.

\section{REFERENCES}

1. Mackey RH, Kuller LH, Moreland LW. Cardiovascular disease risk in patients with rheumatic diseases. Clin Geriatr Med 2017;33:105-17.

2. Mellana WM, Aronow WS, Palaniswamy C, et al. Rheumatoid arthritis: cardiovascular manifestations, pathogenesis, and therapy. Curr Pharm Des 2012;18:1450-6.

3. Nurmohamed MT, Heslinga M, Kitas GD. Cardiovascular comorbidity in rheumatic diseases. Nat Rev Rheumatol 2015;11:693-704.

4. Skeoch S, Bruce IN. Atherosclerosis in rheumatoid arthritis: is it all about inflammation? Nat Rev Rheumatol 2015;11:390-400.

5. Breland UM, Hollan I, Saatvedt K, et al. Inflammatory markers in patients with coronary artery disease with and without inflammatory rheumatic disease. Rheumatology 2010;49:1118-27.

6. Hartman J, Frishman WH. Inflammation and atherosclerosis: a review of the role of interleukin- 6 in the development of atherosclerosis and the potential for targeted drug therapy. Cardiol Rev 2014;22:147-51.

7. Gonzalez-Gay MA, Gonzalez-Juanatey C, Piñeiro A, et al. Highgrade C-reactive protein elevation correlates with accelerated atherogenesis in patients with rheumatoid arthritis. J Rheumatol 2005;32:1219-23.

8. Gonzalez-Gay MA, Gonzalez-Juanatey C, Lopez-Diaz MJ, et al. HLA-DRB1 and persistent chronic inflammation contribute to cardiovascular events and cardiovascular mortality in patients with rheumatoid arthritis. Arthritis Rheum 2007:57:125-32.

9. López-Mejías R, Castañeda S, González-Juanatey C, et al. Cardiovascular risk assessment in patients with rheumatoid arthritis: The relevance of clinical, genetic and serological markers. Autoimmun Rev 2016;15:1013-30.

10. Niccoli G, Cin D, Scalone G, et al. Lipoprotein (a) is related to coronary atherosclerotic burden and a vulnerable plaque phenotype in angiographically obstructive coronary artery disease. Atherosclerosis 2016;246:214-20.

11. Manocha A, Srivastava LM. Lipoprotein (a): a Unique Independent Risk Factor for Coronary Artery Disease. Indian J Clin Biochem 2016;31:13-20.

12. Nordestgaard BG, Langsted A. Lipoprotein (a) as a cause of cardiovascular disease: insights from epidemiology, genetics, and biology. J Lipid Res 2016;57:1953-75.

13. Gurdasani D, Sjouke B, Tsimikas S, et al. Lipoprotein(a) and risk of coronary, cerebrovascular, and peripheral artery disease: the EPICNorfolk prospective population study. Arterioscler Thromb Vasc Biol 2012;32:3058-65.

14. Boffa MB, Koschinsky ML. Lipoprotein (a): truly a direct prothrombotic factor in cardiovascular disease? $J$ Lipid Res 2016:57:745-57.

15. Schultz O, Oberhauser F, Saech J, et al. Effects of inhibition of interleukin-6 signalling on insulin sensitivity and lipoprotein (a) levels in human subjects with rheumatoid diseases. PLoS One 2010;5:e14328

16. Hjeltnes G, Hollan I, Førre O, et al. Serum levels of lipoprotein(a) and E-selectin are reduced in rheumatoid arthritis patients treated with methotrexate or methotrexate in combination with TNF- $\alpha$-inhibitor. Clin Exp Rheumatol 2013;31:415-21.

17. Boffa MB. Emerging Therapeutic Options for Lowering of Lipoprotein(a): Implications for Prevention of Cardiovascular Disease. Curr Atheroscler Rep 2016;18:69.

18. van Capelleveen JC, van der Valk FM, Stroes ES. Current therapies for lowering lipoprotein (a). J Lipid Res 2016;57:1612-8.

19. Missala I, Kassner U, Steinhagen-Thiessen E. A Systematic Literature Review of the Association of Lipoprotein(a) and Autoimmune Diseases and Atherosclerosis. Int J Rheumatol 2012;2012:1-10.

20. Hollan I, Bottazzi B, Cuccovillo I, et al. Increased levels of serum pentraxin 3, a novel cardiovascular biomarker, in patients with inflammatory rheumatic disease. Arthritis Care Res 2010;62:378-85.

21. Hollan I, Scott H, Saatvedt K, et al. Inflammatory rheumatic disease and smoking are predictors of aortic inflammation: a controlled study of biopsy specimens obtained at coronary artery surgery. Arthritis Rheum 2007;56:2072-9.

22. Gabay C, Mclnnes IB, Kavanaugh A, et al. Comparison of lipid and lipid-associated cardiovascular risk marker changes after treatment with tocilizumab or adalimumab in patients with rheumatoid arthritis. Ann Rheum Dis 2016:75:1806-12.

23. Müller N, Schulte DM, Türk K, et al. IL-6 blockade by monoclonal antibodies inhibits apolipoprotein (a) expression and lipoprotein (a) synthesis in humans. J Lipid Res 2015;56:1034-42.

24. García-Gómez C, Martín-Martínez MA, Castañeda S, et al. Lipoprotein(a) concentrations in rheumatoid arthritis on biologic therapy: Results from the CARdiovascular in rheuMAtology study project. J Clin Lipidol 2017;11:749-56.

25. Ueland T, et al. Serum lipoprotein(a) is not modified by interleukin- 6 receptor antagonism or associated with inflammation in non-STelevation myocardial infarction. Int J Cardiol 2018.

26. Sharma S, Merchant J, Fleming SE. Lp(a)-cholesterol is associated with HDL-cholesterol in overweight and obese African American children and is not an independent risk factor for CVD. Cardiovasc Diabetol 2012;11:10.

27. Afshar M, Pilote L, Dufresne L, et al. Lipoprotein(a) Interactions With Low-Density Lipoprotein Cholesterol and Other Cardiovascular Risk Factors in Premature Acute Coronary Syndrome (ACS). J Am Heart Assoc 2016;5.

28. Puri R, Ballantyne CM, Hoogeveen RC, et al. Lipoprotein(a) and coronary atheroma progression rates during long-term highintensity statin therapy: Insights from SATURN. Atherosclerosis 2017;263:137-44. 